\title{
In-situ synthesis and sintering of mullite glass composites by SPS
}

\author{
Jinyong ZHANG ${ }^{a}{ }^{*}$, Hai ZHAN ${ }^{a}$, Zhengyi FU ${ }^{a}$, Richard TODD ${ }^{b}$ \\ ${ }^{a}$ State Key Laboratory of Advanced Technology for Materials Synthesis and Processing, Wuhan University of \\ Technology, Wuhan 430070, China \\ ${ }^{b}$ Department of Materials, University of Oxford, Oxford, UK
}

Received: March 24, 2014; Revised: April 25, 2014; Accepted: April 27, 2014

CThe Author(s) 2014. This article is published with open access at Springerlink.com

\begin{abstract}
The main subject of this work is an investigation of the effects of heating rate and current on the crystallisation of amorphous precursors in spark plasma sintering (SPS). For this, dry gel of $\mathrm{Al}_{2} \mathrm{O}_{3}-\mathrm{SiO}_{2}$ with a molar ratio of 1:1, was synthesized and sintered in-situ by SPS, and also by hot pressing (HP) for comparison. Phase analysis showed that the only crystalline product in both cases was mullite, whose $\mathrm{Al}_{2} \mathrm{O}_{3}$ content was lower in the SPS specimens. The microstructures showed a low volume fraction of large mullite fibers in the SPS specimens, whereas a high volume fraction of fine equiaxed grains was present in the HP specimen. The main difference in microstructure between HP and SPS specimens could be explained in terms of the higher heating rate of the SPS specimens. The size of the SPS die also affected the size and aspect ratio of the mullite fibers produced, which might have been due to either the different electrical current required or a difference in specimen temperature profile.
\end{abstract}

Keywords: spark plasma sintering (SPS); synthesis; extra-field; mullite

\section{Introduction}

A key difficulty in producing fine grained ceramics is the attainment of full density without allowing excessive grain growth. This is a severe limitation with conventional sintering processes [1]. A recently introduced method of overcoming this problem is so-called spark plasma sintering (SPS), also known as field assisted sintering technology (FAST). The process resembles conventional hot pressing, but with much higher heating rate owing to direct heating of the graphite die or the sintering precursor itself by passing direct current (DC) through it. This allows the rapid sintering of powders as well as the production of

\footnotetext{
* Corresponding author.

E-mail: jyzhang@whut.edu.cn
}

metastable phase compositions. It remains a matter for debate that whether the novel microstructures produced are simply a consequence of the rapid heating or a result of the electric field or current involved [2-5].

Recently, Galy et al. [6] found that SPS can also provide a novel synthesis method for ceramics. In that case, SPS synthesis is investigated in $\mathrm{M}-\mathrm{V}-\mathrm{O}$ systems $(\mathrm{M}=\mathrm{Cu}, \mathrm{Ag}, \mathrm{Zn}, \mathrm{CuZn})$. In classical solid state synthesis, synthesis of $\mathrm{M}_{x} \mathrm{~V}_{2} \mathrm{O}_{5}$ phases requires careful grinding of the corresponding powders and long treatments (e.g., 2 days) in sealed quartz tubes at $600{ }^{\circ} \mathrm{C}$; however, in SPS, they are formed in only a few minutes. This success is attributed to $M$ atoms penetrating micro-crystals of $\mathrm{V}_{2} \mathrm{O}_{5}$ oxide at high speed, which shear the original crystal network and rebuild the crystal as one of the new products reported. The driving forces for the penetration of $\mathrm{M}$ atoms are not 
identified with certainty. However, compared with normal solid phase synthesis, which usually has a long (slow) heating and holding period, the fast heating and cooling available with SPS allow processing far from equilibrium, so the possibility of new chemical reactions being available is to be expected, as described in Refs. [6,7].

The remarkable behavior of SPS processing has become a focus of attention recently, and especially the discussion of the thermal and athermal mechanisms may be involved [4]. In order to investigate the effect of SPS in systems where chemical reaction or crystallisation occurs in addition to the usual sintering mechanisms, the effect of SPS on an amorphous dry gel of $\mathrm{Al}_{2} \mathrm{O}_{3}-\mathrm{SiO}_{2}$ was chosen. This is a well known system whose phase equilibria, reaction kinetics and grain growth have been studied widely in conventional conditions. Simultaneous crystallisation and sintering by SPS have been compared with the results from conventional hot pressing (HP). The SPS die dimensions have also been varied in an attempt to vary the electric current/field, which has been reported to be important in affecting grain growth in conventional sintering, for example [8-10].

\section{Experimental}

Commercial tetraethylorthosilicate $\left(\mathrm{Si}_{(}\left(\mathrm{OC}_{2} \mathrm{H}_{5}\right)_{4}, \mathrm{TEOS}\right)$ and aluminum ethoxide $\left(\mathrm{Al}\left(\mathrm{OC}_{2} \mathrm{H}_{5}\right)_{3}\right)$ with a molar ratio of $1: 1$, were used as precursors for $\mathrm{SiO}_{2}$ and $\mathrm{Al}_{2} \mathrm{O}_{3}$, respectively. The well-mixed combination of TEOS and aluminum ethoxide in ethanol was put in an oven at $60{ }^{\circ} \mathrm{C}$ for $72 \mathrm{~h}$ to prepare a wet gel and then dried at $100{ }^{\circ} \mathrm{C}$ for $72 \mathrm{~h}$. In order to remove residual organic components and any remaining water, the dried gel was heated to $600{ }^{\circ} \mathrm{C}$ for $10 \mathrm{~h}$.

The in-situ synthesis and sintering of dried gel powders were performed in graphite dies in an SPS machine (SPS-1050, SPS Syntex Inc., Japan) and an HP machine (HP-620, ATI Inc., USA) with the same sintering temperature of $1300{ }^{\circ} \mathrm{C}$ and pressure of 30 $\mathrm{MPa}$ under vacuum $\left(10^{-4}\right.$ bar). The atmospheric conditions are believed to be reducing owing to the graphite dies. Heating and soaking time were $3 \mathrm{~min}$ and $15 \mathrm{~min}$ respectively in SPS, and $90 \mathrm{~min}$ and $60 \mathrm{~min}$ in HP respectively. After synthesis and sintering, all specimens were cooled naturally in the furnaces.
Two graphite dies with the same inner diameter of $10 \mathrm{~mm}$ and different outer diameters of $30 \mathrm{~mm}$ and $45 \mathrm{~mm}$ were utilized to achieve changes in the electrical parameters of the SPS machine. The currents required by the two dies to maintain the same sintering temperature were about $860 \mathrm{~A}$ and $1227 \mathrm{~A}$ during the holding time, respectively. For the same reason, the currents in the two dies during the heating period also differed to achieve the same average heating rate. Results showed that the current in SPS with $1227 \mathrm{~A}$ required was higher than that of SPS with $860 \mathrm{~A}$ required during most of the heating period. These differences are a consequence of the different electrical resistances and heat flow of the dies. In the following, the specimens are referred to as SPS-860 and SPS-1227 and the hot pressed specimen as HP for convenience.

Phases present in the products were investigated via X-ray diffraction (XRD, Ultima III, Rigaku, Japan) using $\mathrm{Cu} \mathrm{K} \alpha$ radiation, and grain shape/size were measured by the linear intercept method via scanning electron microscopy (SEM, FEI-Sirion200, Amsterdam, the Netherlands) and transmission electron microscopy (TEM, JEM-2010F, JEOL, Tokyo, Japan). SEM specimens were polished, etched with nitrohydrochloric acid and coated with carbon. In addition, the mechanical properties of the different microstructures produced were investigated by Vickers indentation.

\section{Results and discussion}

\section{1 Phase composition and microstructure}

Figure 1 shows XRD patterns of specimens fabricated by SPS and HP. The main crystalline product found in all three samples is mullite. No cristobalite or corundum is found, as reported in Ref. [11]. In Fig. 1, there is also an evidence of amorphous phase towards the lowest diffraction angle used in the scan of $25^{\circ}$, particularly for the SPS-1227 specimen. The presence of an amorphous phase is confirmed by its dissolution in nitrohydrochloric acid (Fig. 2). The amorphous phase is believed to be primarily a consequence of the 1:1 molar ratio of $\mathrm{Al}_{2} \mathrm{O}_{3}: \mathrm{SiO}_{2}$ in the raw gel, which leads to an excess of $\mathrm{SiO}_{2}$ compared with the usual mullite compositions, which lie between $3 \mathrm{Al}_{2} \mathrm{O}_{3} \cdot 2 \mathrm{SiO}_{2}$ and $2 \mathrm{Al}_{2} \mathrm{O}_{3} \cdot \mathrm{SiO}_{2}$. 


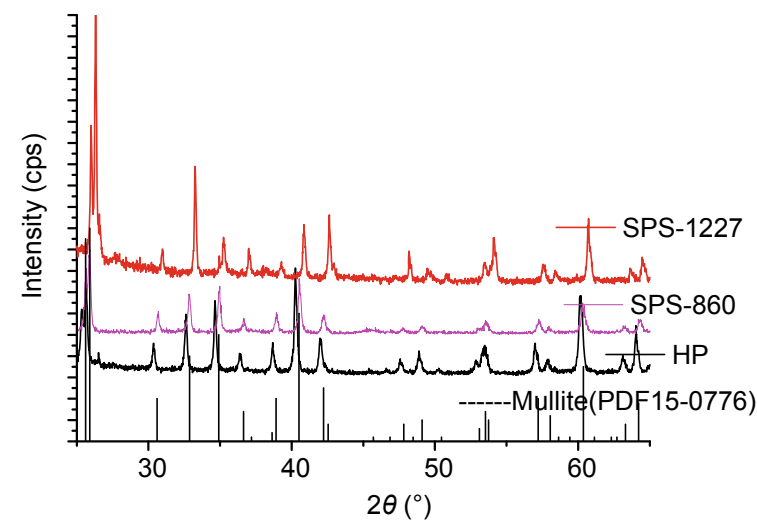

Fig. 1 XRD results of products fabricated by SPS and HP.

Although all the crystalline products are mullite, the actual stoichiometric ratio varies among specimens and can be estimated from the lattice constants deduced from the XRD patterns. The peak positions in SPS-1227 here are slightly shifted to higher $2 \theta$ values than those of standard $3 \mathrm{Al}_{2} \mathrm{O}_{3} \cdot 2 \mathrm{SiO}_{2}$ mullite (JCPDS Card No. 15-0776, see Fig. 1), while those of SPS-860 and HP have lower $2 \theta$ values. Cameron [12] and Schneider et al. [13] have reviewed the relationship between the lattice constant of mullite and $\mathrm{Al}_{2} \mathrm{O}_{3}$ molar content in mullite. Higher cell volumes, corresponding to peak positions shifted to lower $2 \theta$ values, are believed to indicate $\mathrm{Al}_{2} \mathrm{O}_{3}$-rich mullite. Therefore, the mullite in the HP specimen has the highest alumina content for its biggest shift to lower $2 \theta$ values in XRD patterns, then SPS-860, and then SPS-1227. This may be because the slow heating of the HP specimen allows sufficient time for the adjustment of the mullite stoichiometry to the favored high alumina compositions further from the gel composition.

Figure 2 shows typical SEM micrographs of acid-etched HP and SPS-1227 specimens. The acid etch preferentially removes the amorphous phase, and considering that the etching is done under the same condition for the two specimens, it is evident that the SPS-1227 specimen contains considerably more amorphous phase than the HP specimen. This is presumed to be because the slower heating of the HP specimen allows more time for crystallisation. There is a very marked contrast in the microstructures produced by SPS and HP with the residual mullite grains in SPS-1227 being large and fiber-like, whereas they are fine and equiaxed in the HP specimen. The fibers visible in the SPS-1227 micrograph have an aspect ratio of $\sim 15$ with typical diameter and length of about
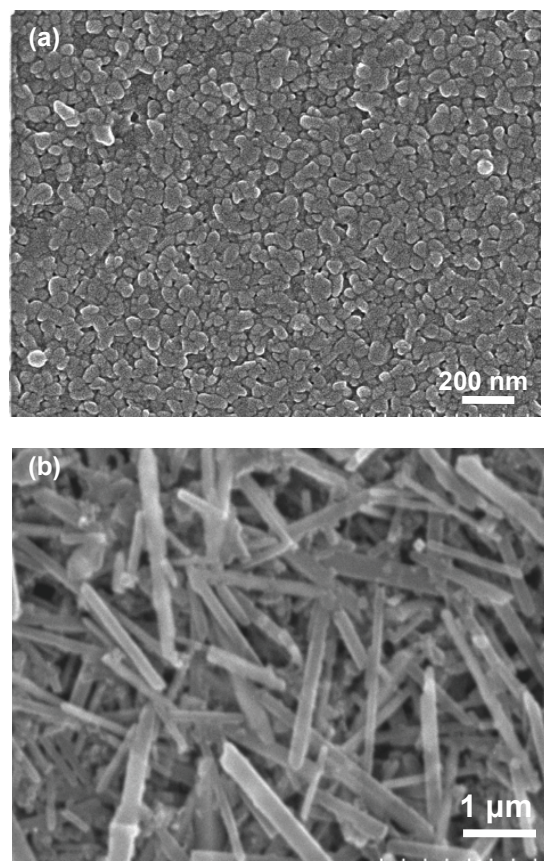

Fig. 2 SEM pictures of (a) HP and (b) SPS-1227 after acid etching.

$200 \mathrm{~nm}$ and $3 \mu \mathrm{m}$ respectively. Both the diameter and length are larger than the average equiaxed HP grain size of $\sim 100 \mathrm{~nm}$. Figure 1 shows that the 120/210 reflection at around $26^{\circ}$ in the SPS-1227 specimen has abnormally high intensity. Since the fibers appear to be lying mainly in the plane of the SPS disc, this suggests that the long axis of the needles is in the [001] direction.

Figure 3 shows TEM micrographs of SPS-860 and SPS-1227 specimens. The SPS-860 specimen also shows elongated mullite grains, but the aspect ratio is much less than that of the SPS-1227 specimen and the grains are finer (n.b., it is thought that the smallest whiskers shown in Fig. 3(b) are not apparent in the SEM micrograph of Fig. 2(b), because they are removed with the glassy matrix during etching of the SPS-1227 specimen).

As with the alumina content of the mullite and the glass content, the different grain size and morphology between the SPS specimens and the HP specimen can be explained classically in terms of the different heating rates. For the HP specimen, with a relatively slow heating rate, the gel spends a lot of time at low temperature, with a big undercooling leading to a lot of nucleation. When the maximum temperature is reached, however, growth occurs quickly from the many, finely spaced nuclei, giving a fine equiaxed grain size. With the rapid heating rate for SPS, however, there is little 

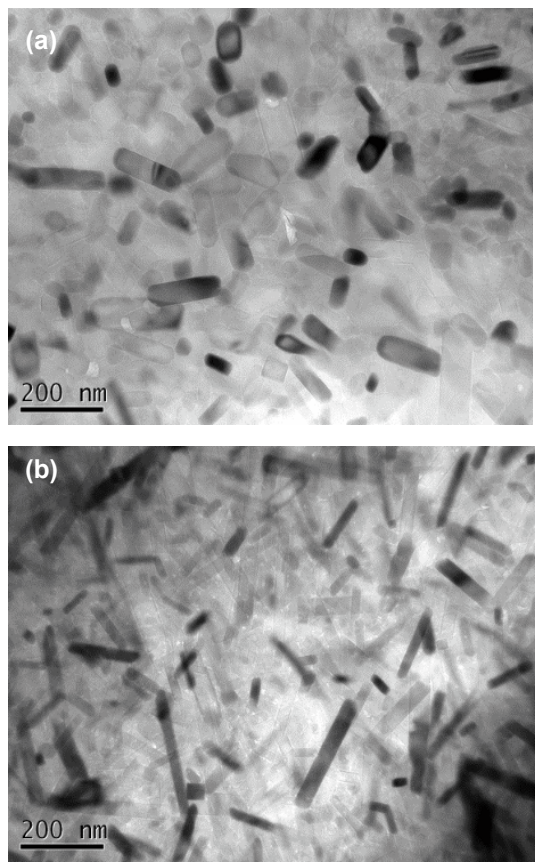

Fig. 3 TEM pictures of (a) SPS-860 and (b) SPS-1227.

time for nucleation at low temperature, so only a few nuclei are formed. The wide spacing of the nuclei then allows the growth at high temperature to occur over long distances without the grains impinging, giving space for the observed fibers to develop.

The differences between the two SPS specimens cannot be explained with certainty with the information available. On one hand, there are reasons to expect differences to arise from the different temperature cycle experienced by the specimens owing to the different dimensions of the dies used. Although the power is controlled to give nominally the same temperature profile in both cases, the temperature is measured using the radiation from a hole drilled in the die. The holes end near the specimens in both dies and it is known that temperature gradients exist during SPS [14], so there may still be temperature differences in the specimens themselves. In addition, the hole used for temperature measurement is necessarily deeper for the larger SPS-1227 die, and this may also produce an apparent temperature difference in the pyrometer measurement, which is unlikely to be able to reflect accurately the precise temperature at the end of the hole in the die.

On the other hand, the die dimensions also affect the electrical current and electromagnetic fields in the vicinity of the specimens. There are many ways to obtain mullite with higher aspect ratio, such as applying high temperature in sintering [15] or adding low melting-point components in liquid-solid reaction synthesis [16]. However, it is noted that the enhanced diffusion of $\mathrm{Si}^{4+}$ ions is believed to be the underlying reason for oriented growth of mullite [15-17]. Several works have shown that electromagnetic field can enhance the movement of ions [8], and it is therefore possible that the field produced in the SPS machine may also have enhanced the diffusion of $\mathrm{Si}^{4+}$ ions, and this is more so in the experiment with the higher SPS current.

The precise conditions of temperature and electromagnetic field at the specimen are difficult to determine under the present conditions, and this debate can only be resolved by further work.

\section{2 Mechanical properties}

Figure 4 shows typical $2 \mathrm{~kg}$ indentations in the HP and SPS-1227 specimens. The indentation in the HP specimen shows ring cracking and spalling typical of anomalous glasses in which the glass densifies under the pressure of the indentation $[18,19]$. The classical radial cracks around the indentation in the SPS- 1227 specimen are more like those in normal ceramics. This is perhaps surprising given the higher glass content but may be explained by the morphology of the long fibers, which could restrain densification of the glass. In contrast, the continuous network of glass between the equiaxed grains of the HP specimen could densify without deformation of the mullite grains. "Fibers" in the form of multiwall carbon nanotubes have been observed to have the same effect [20] in suppressing such indentation behavior in anomalous glasses. The high magnification picture in Fig. 4(c) shows bridge-like structures across the crack. These may be the fiber-like mullite grains. Such bridging offers the possibility of toughening although detailed measurements of toughness would be needed to confirm this.

\section{Conclusions}

$\mathrm{Al}_{2} \mathrm{O}_{3}-\mathrm{SiO}_{2}$ gels have been densified by SPS and HP. The two processes lead to markedly different microstructures, with fine equiaxed grains formed in HP and an in-situ composite structure consisting of mullite needles in a glassy matrix in SPS. It is suggested that the primary reason for the differences is 

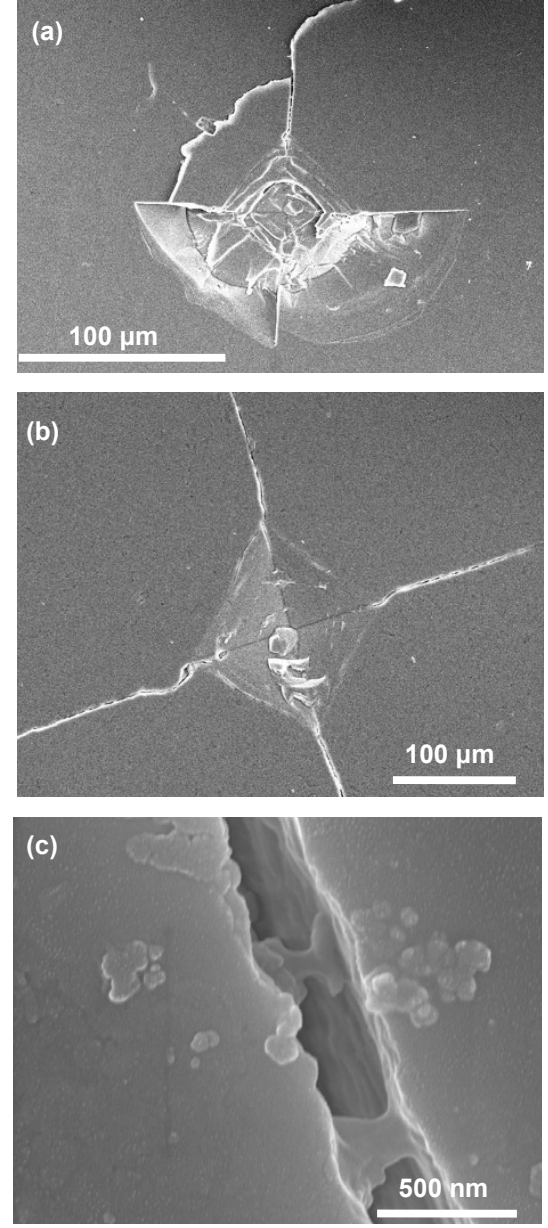

Fig. 4 SEM pictures of (a) HP and (b) and (c) SPS-1227 specimens after $2 \mathrm{~kg}$ indentation.

that the rapid heating rate in SPS suppresses the nucleation of crystallisation because of the short time spent in the low temperature part of the heating cycle. The size of the SPS die also affects the microstructure and this may be a result of different temperatures and/or electromagnetic fields experienced by the specimens. The paper demonstrates that SPS can be used to produce strikingly novel microstructures by crystallisation of amorphous precursors.

\section{Acknowledgements}

The authors acknowledge the support of the National Natural Science Foundation of China (U12301013) and the State Key Lab of Material Synthesis and Technology (Contract No. 201106) for the financial support. The authors also want to thank Dr. Bryan Tsu Te Chu from the Department of Materials, University of Oxford, for discussions.
Open Access: This article is distributed under the terms of the Creative Commons Attribution License which permits any use, distribution, and reproduction in any medium, provided the original author(s) and the source are credited.

\section{References}

[1] Roy JF, Descemond M, Brodhag C, et al. Alumina microstructural behaviour under pressureless sintering and hot-pressing. J Eur Ceram Soc 1993, 11: 325-333.

[2] Conrad H, Yang D. Dependence of the sintering rate and related grain size of yttria-stabilized polycrystalline zirconia (3Y-TZP) on the strength of an applied DC electric field. Mat Sci Eng A 2011, 528: 8523-8529.

[3] Olevsky EA, Kandukuri S, Froyen L. Consolidation enhancement in spark-plasma sintering: Impact of high heating rates. J Appl Phys 2007, 102: 114913.

[4] Holland TB, Tran TB, Quach DV, et al. Athermal and thermal mechanisms of sintering at high heating rates in the presence and absence of an externally applied field. J Eur Ceram Soc 2012, 32: 3675-3683.

[5] Gendre M, Maitre A, Trolliard G. A study of the densification mechanisms during spark plasma sintering of zirconium (oxy-)carbide powders. Acta Mater 2010, 58: 2598-2609.

[6] Galy J, Dolle M, Hungria T, et al. A new way to make solid state chemistry: Spark plasma synthesis of copper or silver vanadium oxide bronzes. Solid State Sci 2008, 10: 976-981.

[7] Wang K-Y. Non-equilibrium chemical reactions with rapid heating and quenching. Energy 1987, 12: 291-302.

[8] Chen S, Wang W, Kono H, et al. Abnormal grain growth of hydroxyapatite ceramic sintered in a high magnetic field. J Cryst Growth 2010, 312: 323-326.

[9] Yang D, Conrad H. Influence of an electric field on grain growth in extruded NaCl. Scripta Mater 1998, 38: 1443-1448.

[10] Conrad H, Guo Z, Sprecher AF. Effect of an electric field on the recovery and recrystallization of $\mathrm{Al}$ and Cu. Scripta Metall 1989, 23: 821-823.

[11] Fischer RX, Schneider H. The mullite-type family of crystal structures. In Mullite. Schneider $\mathrm{H}$, Komarneni S, Eds. John Wiley \& Sons, 2006: 93-128.

[12] Cameron WE. Mullite: A substituted alumina. Am Mineral 1977, 62: 747-755.

[13] Schneider H, Fischer RX, Voll D. Mullite with lattice contents $a>b . \quad J$ Am Ceram Soc 1993, 76: 
1879-1881.

[14] Anselmi-Tamburini U, Gennari S, Garay JE, et al. Fundamental investigations on the spark plasma sintering/synthesis process: II. Modeling of current and temperature distributions. Mat Sci Eng A 2005, 394: 139-148.

[15] Ghate BB, Hasselmann DPH, Spriggs RM. Kinetics of pressure-sintering and grain-growth of ultra-fine mullite powder. Ceram Int 1975, 1: 105-110.

[16] Huang TH, Rahaman MN, Mah T-I, et al. Anisotropic grain growth and microstructural evolution of dense mullite above $1550{ }^{\circ} \mathrm{C} . \mathrm{J} \mathrm{Am}$ Ceram Soc 2000, 83: 204-210.

[17] Lee J-E, Kim J-W, Jung Y-G, et al. Effects of precursor $\mathrm{pH}$ and sintering temperature on synthesizing and morphology of sol-gel processed mullite. Ceram Int 2002, 28: 935-940.

[18] Arora A, Marshall DB, Lawn BR. Indentation deformation/fracture of normal and anomalous glasses. J Non-Cryst Solids 1979, 31: 415-428.

[19] Bertoldi M, Sglavo VM. Soda-borosilicate glass: Normal or anomalous behavior under Vickers indentation? J Non-Cryst Solids 2004, 344: 51-59.

[20] Mukhopadhyay A, Chu BTT, Green MLH, et al. Understanding the mechanical reinforcement of uniformly dispersed multiwalled carbon nanotubes in alumino-borosilicate glass ceramic. Acta Mater 2010, 58: 2685-2697. 